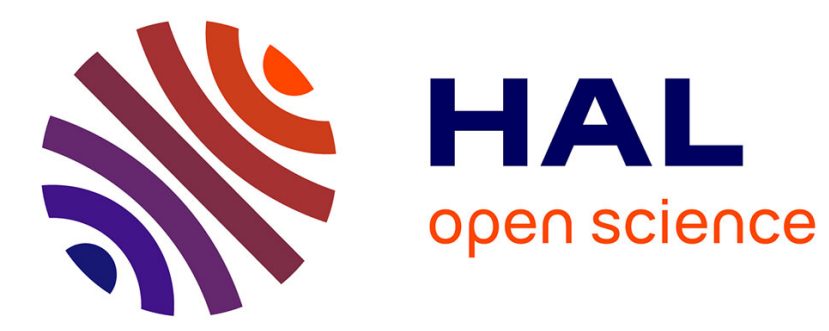

\title{
The Chemical Nature of Oxidized Sulphur in Asphaltenes from X-Ray Absorption Spectroscopy
}

\author{
M. Kasrai, G. Bancroft, R. Brunner, J. Connan
}

\section{To cite this version:}

M. Kasrai, G. Bancroft, R. Brunner, J. Connan. The Chemical Nature of Oxidized Sulphur in Asphaltenes from X-Ray Absorption Spectroscopy. Journal de Physique IV Proceedings, 1997, 7 (C2), pp.C2-809-C2-810. 10.1051/jp4:1997241 . jpa-00255320

\section{HAL Id: jpa-00255320 https://hal.science/jpa-00255320}

Submitted on 1 Jan 1997

HAL is a multi-disciplinary open access archive for the deposit and dissemination of scientific research documents, whether they are published or not. The documents may come from teaching and research institutions in France or abroad, or from public or private research centers.
L'archive ouverte pluridisciplinaire HAL, est destinée au dépôt et à la diffusion de documents scientifiques de niveau recherche, publiés ou non, émanant des établissements d'enseignement et de recherche français ou étrangers, des laboratoires publics ou privés. 


\title{
The Chemical Nature of Oxidized Sulphur in Asphaltenes from X-Ray Absorption Spectroscopy
}

\author{
M. Kasrai, G.M. Bancroft, R. Brunner and J. Connan* \\ Department of Chemistry, University of Western Ontario, London, Ontario N6A 5B7, Canada \\ * Exploration Direction, Elf Aquitaine, CSTJF, 64018 Pau cedex, France
}

\begin{abstract}
Bitumen samples have been chosen either from natural oil seepages and outcropping oil-stained reservoirs or archaeological bitumens from excavations in Iraq and Pakistan. Asphaltenes have been extracted from the bitumens. X-ray absorption near edge fine structure (XANES) spectroscopy at the S L-edge and K-edge has been employed to follow the oxidation effects on various sulphur moieties of the asphaltene fractions. Among asphaltenes extracted from archeological bitumens, sulphoxide, sulphone and sulphate are the predominant oxidized forms of sulphur.
\end{abstract}

\section{INTRODUCTION}

Natural asphatts were widely used in the ancient world to make ornamental objects, to pave roads, to waterproof pipes and also used as an adhesive. In Egypt, the material was extensively used as one of the ingredient of balms in mummies [1]. In the course of time, asphalts and bitumens are subjected to numerous alteration processes such as water washing, evaporation, oxidation and biodegradation. For example, it has been shown that the oxidation of bitumens results in oxygen incorporation into organic molecular structure which leads to decrease in the proportion of free aromatics and increase in the macromolecular fraction [2]. Asphaltene (macromolecules) extracted from bitumens, depending on the location, contain significant amounts of sulphur ( 2-6\%). Sulphur is bonded to carbon and is the integral part of the molecule. It is thus expected that $\mathrm{S}$ will also undergo similar alteration.

In this study, in order to explore this possibility, sulphur oxidation in several asphaltene samples extracted from bitumens have been investigated using S K-edge and L-edge XANES spectroscopy [3]

\section{EXPERIMENTAL}

Asphaltenes have been extracted from bitumen samples from various localities in Iraq, Pakistan and Syria and been chosen either among natural oil seepages and outcropping oil-stained reservoirs or archaeological bitumens from excavations in the Near East. Photoabsorption spectra at the S K-edge (2460-2520 eV) and L-edge (160-200 eV) were recorded at the Canadian Synchrotron Radiation Facility situated on the $1 \mathrm{GeV}$ electron storage ring, Aladdin, University of Wisconsin. The details of the data recording and analysis have been reported before[4].

\section{RESULTS AND DISCUSSION}

Table 1 summarises the specifications of a few selected samples used in this study. It is well established that bitumens used in the mortars of Babylonian Palaces originates from bitumens in Hit areas in Iraq. Hit235 is from a live oil seep in the Hit village and Hit233 comes from a carbonate cliff close to the village. Bib227 is taken from the wall of the South Palace in Babylon. The isotopic data $\left({ }^{13} \mathrm{C}\right.$ values) of asphaltene, quoted in Table 1 are reliable genetic parameters which are not affected by secondary alteration processes and consequently can be used to trace the origin of the archeological samples [5]. Based on the isotopic data given in Table 1, the two Hit samples and Bib227 have the same origin. As noted in the Table, the amount of asphaltene extract has increased from. live oil (Hit235) to the archeological sample (Bab227) which indicate that extensive alteration has taken place. Oxidation is one of the effective alteration processes which entails severe compositional changes [2]. Another set of samples in Table 1 come from Pakistan. The isotopic data indicate that the archeological bitumen (Meh335, 5000 BC) from Mehrgahr excavation and samples (Gok330 and Gok326) taken from a nearby village have the same origin, but the asphaltene content of the samples is quite different

It has been shown in the past that S K-edge and L-edge can be used very effectively to characterize the sulphur forms in bitumens and asphaltene [3]. Figure 1 shows the S K-edge XANES spectra of the samples. Using model compounds, it has been established that, peak 1 corresponds to the reduced forms of sulphur (alkyl and thiophenic), and peaks 2-4 to sulphoxide, sulphone and sulphate (and partially sulphonic acid sait), respectively [3]. Spectrum (A) of Hit235 of the live oil, does not exhibit peaks 2, 3 and 4 and thus is free from the oxidized forms of sulphur. Peak $a$ and $b$ are post-edge features of thiophenic sulphur. The other spectra (B-E) point to substantial oxidation of the asphaltenes.

In order to estimate the amount of the oxidised sulphur forms in the samples, a curve fitting procedure described before has been used [4]. Briefly a linear combination of spectra of model compounds representing the oxidised sulphur forms have been used 
Table 1. specification of bitumen and extracted asphaltene samples

\begin{tabular}{|l|l|l|c|c|c|c|c|c||}
\hline Sample & sample description & $\begin{array}{l}\text { chloroform } \\
\text { extraction } \\
(\%)\end{array}$ & $\begin{array}{c}\text { asphaltene } \\
(\%)\end{array}$ & $\begin{array}{c}\mathbf{8}^{13} \mathbf{C} \\
\text { asphaltene } \\
(\%)\end{array}$ & $\begin{array}{c}\text { 6 D } \\
\text { asphaltene } \\
(\%)\end{array}$ & $\begin{array}{c}\text { sulphoxide } \\
(\%)\end{array}$ & $\begin{array}{c}\text { sulphone } \\
(\%)\end{array}$ & $\begin{array}{c}\text { sulphate } \\
(\%)\end{array}$ \\
\hline Hit235 & live oil (Iraq) & 100 & 17.5 & -28.2 & -101 & not detected & not detected & not detected \\
\hline Hit233 & pure bitumen (Iraq) & 56.7 & 39.4 & -28.2 & -88 & not detected & not detected & 15 \\
\hline Bab227 & $\begin{array}{l}\text { archeological } \\
\text { bitumen (Iraq) }\end{array}$ & 25.1 & 74.4 & -28 & -79 & 5 & 15 & 15 \\
\hline Gok330 & live oil (Pakistan) & 100 & 24.3 & -21.8 & -102 & 10 & 13 & 7 \\
\hline Gok326 & $\begin{array}{l}\text { dry oil-stained rock } \\
\text { (Pakistan) }\end{array}$ & 24.6 & 63.7 & -22.5 & -84 & 15 & 10 & 30 \\
\hline Meh335 & $\begin{array}{l}\text { archeological } \\
\text { bitumen (Pakistan) }\end{array}$ & 24 & 80.9 & -20.7 & -63 & 10 & 32 & 16 \\
\hline
\end{tabular}

to simulate the experimental spectra. In this study, the spectrum of Hit235, as a base spectrum, has been linearly combined with different proportions with the spectra of oxidised model compounds. The resultant spectra are shown (dashed line) in Figure 1 along with the experimental spectra (solid line). Table 1(last 3 columns) shows the proportion of sulphoxide, sulphone and sulphate in asphaltene samples. Sulphonic acid salt was also used to simulate the spectra, but its contribution was found to be very small. It is noticed from Table 1 that while Hit 235 contains no sulphate, Hit 233 has up to $15 \%$ sulphate. Since $\mathrm{Ca}$ was also detected in these samples, it is possible that sulphate originate from gypsum (CaSO4) incorporated in bitumen. The same amount of sulphate is found in Bab227. However, Bab227 contains sulphoxide and sulphone which indicates that the archeological specimen has undergone further oxidation in the course of time.

The presence of sulphate in Gok330, Gok326and Meh335 can again originate from mineral (gypsum) incorporation. Ca was also detected in these samples. The proportion of sulphoxide and sulphone in Gok samples are very similar which shows the sample has not been altered further. The archeological sample Meh335 however, has undergone further oxidation. The above results have shown that the XANES analysis of sulphur in asphaltenes can be used to trace the origin and alteration history of the bitumens. It also largely contributes to the accurate definition of the extent of biodegradation and oxidation in the specimens.

\section{Acknowledgement}

This study was financially supported by the National Research Council of Canada, and the Natural Science and Engineering Research Council of Canada. We are grateful to Dr. Kim Tan from CSRF and the staff of the Synchrotron Radiation Centre (SRC), University of Wisconsin, Madison, for their technical support and National Science Foundation (NSF) for supporting the SRC under Award \# DMR-95-31009.

\section{References}

[1] Connan, J., Nissenbaum, A. and Dessort, D., Geochim. Cosmochim. Acta 56 (1992) 2743-2759,

[2] Lemoine, S., Adam, P., Connan, J. and Albrecht, P. in "Organic Geochemistry: Developments, and applications to energy, climate, environment and human history, J. Grimalt and C. Dorronsoro (Eds) (Donostia,San Sebastian, 1995) pp.586-587.

[3] Kasrai, M: Bancroft, G.M. Brunner, R.W., Jonasson, R.G., Brown, J.R., Tan, K.H. and Feng, X., Geochim. Cosmochim. Acta 58 (1994) 2865-2872.

[4] Kasrai, M., Brown, J.R., Bancroft, G.M., Yin, Z. and Tan, K.H., Int. J. Coal Geol. (In press).

[5] Connan, J. and Deschesne, O., "Bitumen at Susa", ( Réunion des Musées Nationaux and Elf, Paris, 1996).

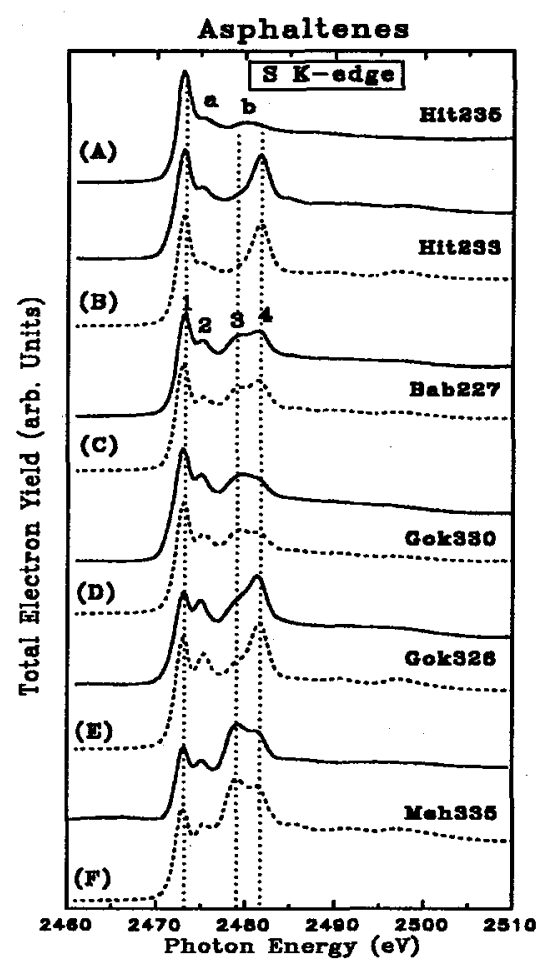

Figure 1: S K-edge XANES spectra of asphaltenes (solid line) and synthetic spectra (dashed line) 